\title{
SMART MOTORCYCLE HELMET: REAL-TIME CRASH DETECTION WITH EMERGENCY NOTIFICATION, TRACKER AND ANTI-THEFT SYSTEM USING INTERNET-OF-THINGS CLOUD BASED TECHNOLOGY
}

\author{
Marlon Intal Tayag ${ }^{1}$ and Maria Emmalyn Asuncion De Vigal Capuno ${ }^{2}$ \\ ${ }^{1}$ College of Information and Communications Technology Holy Angel University, \\ Angeles, Philippines \\ ${ }^{2}$ Faculty of Information Technology Future University, Khartoum, Sudan
}

\begin{abstract}
Buying a car entails a cost, not counting the day to day high price tag of gasoline. People are looking for viable means of transportation that is cost-effective and can move its way through traffic faster. In the Philippines, motorcycle was the answer to most people transportation needs. With the increasing number of a motorcycle rider in the Philippines safety is the utmost concern. Today technology plays a huge role on how this safety can be assured. We now see advances in connected devices. Devices can sense its surrounding through sensor attach to it. With this in mind, this study focuses on the development of a wearable device named Smart Motorcycle Helmet or simply Smart Helmet, whose main objective is to help motorcycle rider in times of emergency. Utilizing sensors such as alcohol level detector, crash/impact sensor, Internet connection thru 3G, accelerometer, Short Message Service (SMS) and cloud computing infrastructure connected to a Raspberry Pi Zero-W and integrating a separate Arduino board for the antitheft tracking module is used to develop the propose Internet-of Things (IoT) device.

Using quantitative method and descriptive type research, the researchers validated the results from the inputs of the participant who tested the smart helmet during the alpha and beta testing process. Taking into account the ethical consideration of the volunteers, who will test the Smart Helmet. To ensure the reliability of the beta and alpha testing, ISO 25010 quality model was used for the assessment focusing on the device accuracy, efficiency and functionality. Based on the inputs and results gathered, the proposed Smart Helmet IoT device can be used as a tool in helping a motorcycle rider when an accident happens to inform the first-responder of the accident location and informing the family of the motorcycle rider.
\end{abstract}

\section{KEYWORDS}

Smart Helmet, Internet of Things, Sensors, Real-Time Crash Detection, Emergency Notification, Tracker, Anti-Theft System Cloud Based Technology

\section{INTRODUCTION}

Buying a car entails a cost, not counting the day to day high price tag of gasoline. People are looking for viable means of transportation that is cost-effective and can move its way through DOI: 10.5121/ijcsit.2019.11307 
traffic faster. In the Philippines, motorcycle was the answer to most people transportation needs.

Designed in 1894, motorcycle or motorbike is a two-wheeled vehicle of which it is estimated that $58 \%$ of them in the world are deployed in Asia-Pacific. With this, motorcycle is now the mainstream transportation for the people who cannot afford to buy their own car and a means of getting from one location to another traversing the road that is jam pack of vehicle congestion. However, it is also the reason why there are a lot of deaths due to motorcycle accidents. As mentioned by Mascarinasthe need for safety regulations must be encouraged paving way for politicians to create laws that will be in effect for better monitoring on the proper use of motorcycle vehicles. [1]

Moreover, according to Philippine Statistic Authority, the number of death caused by road crash accidents has increased from 2006 to up to the present, and motorcycle ranks as the number one with more the 4,872,065 accidents (K. Sy, n.d.). 53\% of all road accidents deaths are from the motorcycle [2] as shown in Table 1.

Table 1.Breakdown of Road Accidents Deaths

\begin{tabular}{|c|c|}
\hline Road deaths & Percentage \\
\hline Motorcycle riders & $53 \%$ \\
\hline Pedestrians & $19 \%$ \\
\hline 4-wheeled vehicle drivers & $14 \%$ \\
\hline 4-wheeled vehicle passengers & $11 \%$ \\
\hline Cyclists & $2 \%$ \\
\hline Others & $1 \%$ \\
\hline
\end{tabular}

Two-wheeled vehicle safety is a must. There are already different types of safety gear on the market. From spinal back-bone protection to the simplest yet neglected safety helmet

As stated by Nandu [3] the helmet plays an important role in protecting the rider from head injuries, wearing it is an important factor in saving the life of the motorcycle rider. But most motorcycle riders tend to neglect in wearing it. Different law has been passed penalizing motorcycle rider who is not wearing one. This affects not only the motorcycle rider but also the people who also ride along with them. Based on the paper by Sung [4], person or individual who is in a motorcycle accident are more unlikely to suffer if they are wearing their helmets such as full face helmet $(\mathrm{FHH})$, open face helmet $(\mathrm{OFH})$ and half-coverage helmet $(\mathrm{HCH})$. A sudden jolt from a crash accident can cause traumatic injuries to the brain and may in long-term complications, brain injuries are the most lethal.

Brain injuries are the most likely cost of death, $40 \%$ of the motorcycle rider will have the highest risk of having brain injury[5]. In the Philippines, it is mandated that every motorcycle rider should wear their helmet. This is stated under the Republic Act No. 10054 or the Motorcycle Helmet Act of 2009. The said law states that it is mandatory to use motorcycle helmets. The use of safety helmets by motorcycle riders have been found to be one of the most effective ways of surviving an accident.

Also, as stated in a paper published by the World Health Organization [6], 90\% of deaths due to motorcycle mishap is due to the driver not wearing any safety helmets. WHO states the data gathered on occurrences of death due to road accidents specifically for a two-wheeled vehicle can be used to improve road safety and rider's awareness on the need of wearing a safety helmet at all times. 
Driving under the influence of alcohol is another mitigating factor in road accidents most specially while driving a two-wheeled motorcycle. A large amount of alcohol in the body while driving affects the driver ability to drive. Such effect includes slow reaction, lack of coordination; decrease vision and can inhibit judgment.

One problem that motorcycle accidents face is having the proper medical treatment. A study [7]made in the United States of America (USA) on road crash injuries states that people die before any hospital treatment to the late arrival of emergency responders. The same is true for those who arrived too late for medical treatment. A golden hour is for saving the victim is sixty minutes after receiving a traumatic injury. This is crucial to reduce the number of victims.

Along with the said injuries caused by motorcycle accidents, motor napping or bike napping is prevalent in the Philippines. As more and more people are choosing this mode of transformation, such a problem arises.

With this, technology will play a large role in saving the lives of these people. One such technology is the Global Positioning System (GPS). GPS is a navigation tool that uses satellites to accurately pinpoint the precise location of the individual. It currently plays a vital role in transportation, rescue, and other industry to name a few. [8]

Arriving on the site of the accident on time is a life or death situation for the people who are at the accident. In the article published by Brodsky [9], he stated that every minute counts when the emergency response team goes out to the accident area. Getting the correct location and the route to that location greatly adds to the timely arrival of the first responders. Sending alert messages to the emergency rescue team is a must. This is where both alert notification and GPS location tracking can be integrated as a technology to save lives which are also calledInternet of Things (IoT). The IoT is a buzzword in today technology-driven infrastructure. Its role is increasing day by day, implemented seamlessly in many of the automated and sensor-based systems. The term IoT was coin by Kevin Ashton in 2003.

Connected devices that talk or communicate with each other using $\mathrm{Wi}-\mathrm{Fi}$, Bluetooth or the network, gathering data using sensors and sending data to the internet for analytics, IoT will encompass a huge number of industries including agriculture, manufacturing, transportation, and security.[10]

Road safety is an area where IoT technology can be implemented. [11]stated in their paper the importance of road safety and how IoT technology will play a part in minimizing road collision. The need for a quick response from the time of the accident to the time of the arrival of the rescue team is vital, in which IoT technology can shorten the gap by means of monitoring of road accidents. Dickenson article clearly describes the crucial role of IoT in road safety, specifically in the transportation area, in which road can become smarter by the used of sensors that can detect environmental reading such as temperature and humidity.[12]

Currently, there have been several implementation of Smart Helmet in several ways. Faizan[13] smart helmet uses GPS and GSM for the sensor monitoring and notification, it works by implementing a vibration sensor as the crash sensor, while researchers [14] used Wi-Fi as the means of communication with Bluetooth for connectivity on the smartphone. 
Another notable project for the smart helmet is by Khaja[15] where IoT integration was done by means of an Arduino module. Each system implementation lacks the combination of each other features. The research goal for this system and hardware development is to combine all the said features and add more, integrating IoT with cloud-based infrastructure. The said features are IoT, Cloud Infrastructure, GPS, Location Tracking, Short Message Service (SMS) / Push Notification along with an alcohol level breath analyzer, integrated with the anti-theft features by sending the GPS location of the motorcycle when stolen.

\section{Conceptual Framework}

Input- Process-Output (IPO) framework was used to guide the researchers in visualizing the required process and output of the study. Monitoring the motorcycle well-being based on real-time data requires the input of multiple sensors which includes a crash sensor for detecting a crash, accelerometer use in conjunction with the crash sensor for detecting speed and impact, GPS to track the motorcycle location by means of its longitude and latitude, data for anti-theft. Alcohol sensor was used to monitor the motorcycle rider alcohol level. All data are sent to the cloud infrastructure for processing. The output is the real-time monitoring of the motorcycle rider current status.

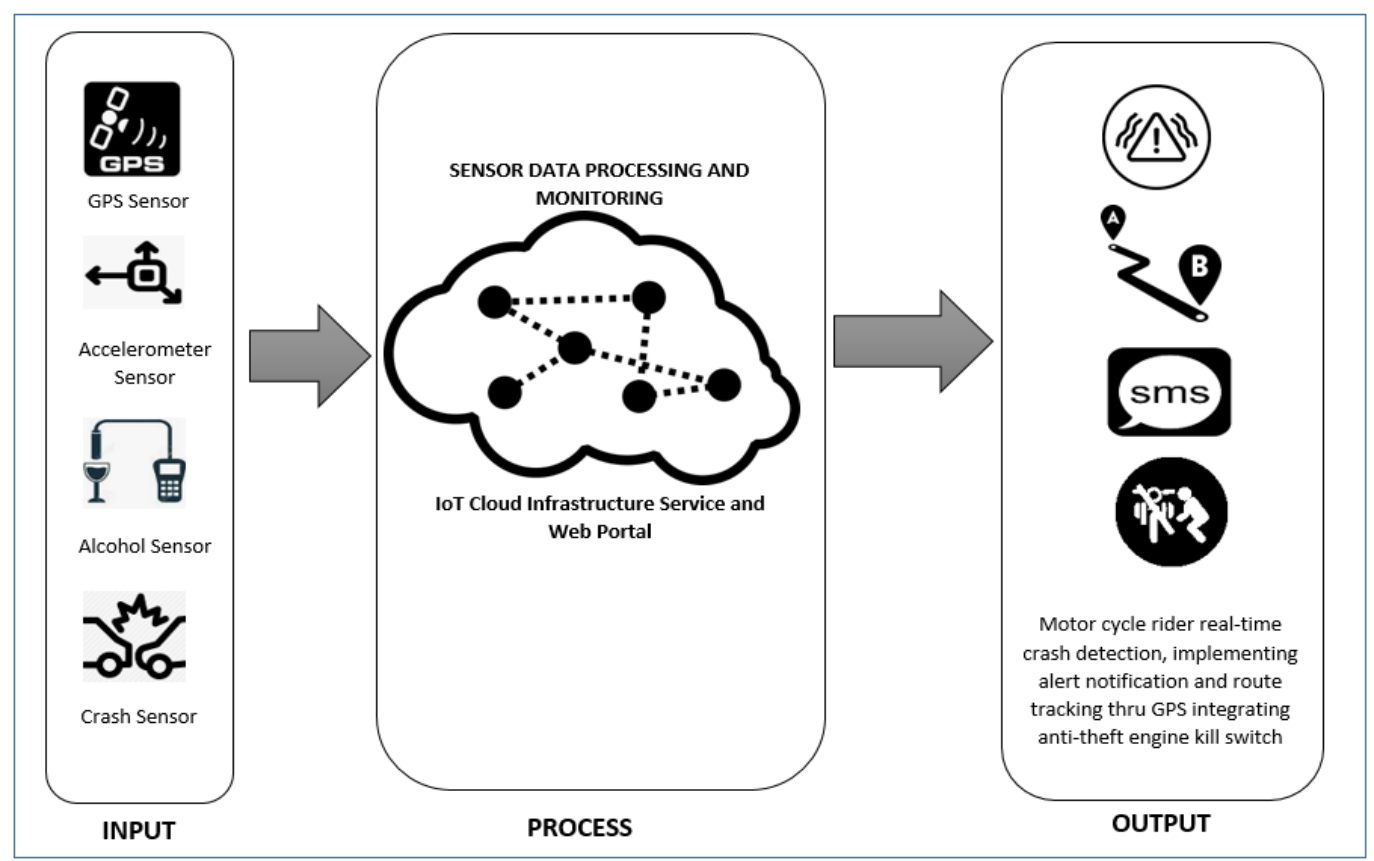

Figure 1. Conceptual Framework

\section{Objectives of the Study}

The main objective of the study was to develop a hardware device and software system for tracking the motorcycle rider real-time safety status. It aimed to achieve the following objectives:

a. To monitor the current location and keep track of the route the motorcycle rider and send SMS notification alert when a collision or crash is detected, sending the GPS location to the 
person of concern (family) related to the motorcycle rider and to the first-responders (emergency personnel) who will come in aid of the motorcycle rider.

b. To check the alcohol level of the motorcycle rider using the alcohol sensor on the helmet and send a notification to the motorcycle rider mobile phone if it is high.

c. To send real-time GPS location to the motorcycle rider when the motorcycle is stolen using the IoT tracking module.

\section{Scope of the Study}

This study focused on the development of the hardware and software system for monitoring the real-time status of the motorcycle rider and the location of the motorcycle in case the said vehicle is stolen. Multiple sensors will be used to monitor the motorcycle rider. The data from the sensor will be sent to the system cloud infrastructure for processing. The respondents and the user will be the motorcycle rider. Any deviation from preset sensor data will trigger an alert. Medical treatment to be done on the motorcycle rider at the accident location is not covered and is beyond the scope of the proposed study.

\section{RESEARCH DESIGN AND DEVELOPMENT}

Both quantitative and descriptive type of research was used by the researchers. It fell under this process because of the need of the researchers to get inputs from the user of the smart helmet, their experience in using it and its effectiveness based on its functionality. This was done by means of conducting an individual test to collect information through surveys and interviews. These surveys lead to the researchers in designing a device that could help motorcycle riders in case of an accident. Testing of the device was needed to ensure the consistency of its performance, data were evaluated and analyzed to see if there were changes or improvements.

\section{Participants}

Purposive homogeneous sampling was used to validate the quality of the collected data. Twentyfive (25) motorcycle riders were selected as respondents in the pre-survey getting the idea of the motorcycle riders safety needs and the problem they face on their day to day commuting and in the post-survey for the testing of the prototype showing the device functionality and performance. The respondents were composed of twenty (20) males and five (5) females, age ranges from 18 to 40 years old.

The researchers chooses to have more male, because of the fact more male use and drive motorcycles for commuting and work and based on the report published by the Transport Accident Commission in 2018 they sum up injuries in female have increased, but male is likely more injured and lose their life in an accident. [16]

Testing of the first prototype did not work as intended, the original hardware to be used as a controller is one single Arduino, due to the different sensors needed to detect the outside environment and taking into account the anti-theft integration using one single Arduino is not enough. Based on the testing of the first prototype and the requirements needed, a second prototype was developed. This time using Raspberry Pi Zero-W as the main controller for the helmet and the Arduino as the controller for the anti-theft module installed on the motorcycle. For the post-survey, a total of ten (10) respondents answered post-survey questionnaires with a 
positive response. The said 10 respondents volunteered to test the working Smart helmet. The second prototype work as expected with the improved device functionality and performance.

\section{Research Instruments}

The researchers used two instruments in this study. First is the pre-survey questionnaire which was used to gather data inputs for the system / IoT development phases. And second, the postsurvey questionnaire to evaluate the accuracy, efficiency, and functionality of the IoT device.

The first phase of the study, a pre-survey questionnaire was used to identify data that are needed in the development of the IoT device, specifically on the needs of the motorcycle rider for a device that can help in an emergency situation such as a collision, accidents or when the motorcycle is stolen.

As this is hardware and software integration of an IoT device, alpha and beta testing was done. For alpha testing, the functionality of the IoT device was tested. This functionality includes (a) connection to GPS Signal, (b) SMS Sending, (c) image capturing; and (d) alcohol detection. Any glitches, errors, and malfunction found were taken into account for the changes needed and integrated to improve the development of the IoT device.

The second phase involves beta testing, these include assessment of the functionality, the effectiveness of the IoT device. The beta testing phase also involves testing of a working version of the smart helmet. Ten (10) motorcycle rider tested the smart helmet with a positive response from them in terms of the functionality of the said device.

To ensure the reliability of the assessment and testing of the IoT device, the researchers made use of the quality model ISO 25010 as the cornerstone in the quality evaluation system. With this model, the following characteristic of the intended device was checked. This features includes namely; accuracy, efficiency, and functionality ("ISO 25010," n.d.).

The researchers used three (3) items; Reliability (Accuracy), Performance efficiency (Efficiency) and Functional suitability (Functionality) out of the eight (8) characteristics in the ISO 25010, which form the basis in the design of the survey questionnaires. 


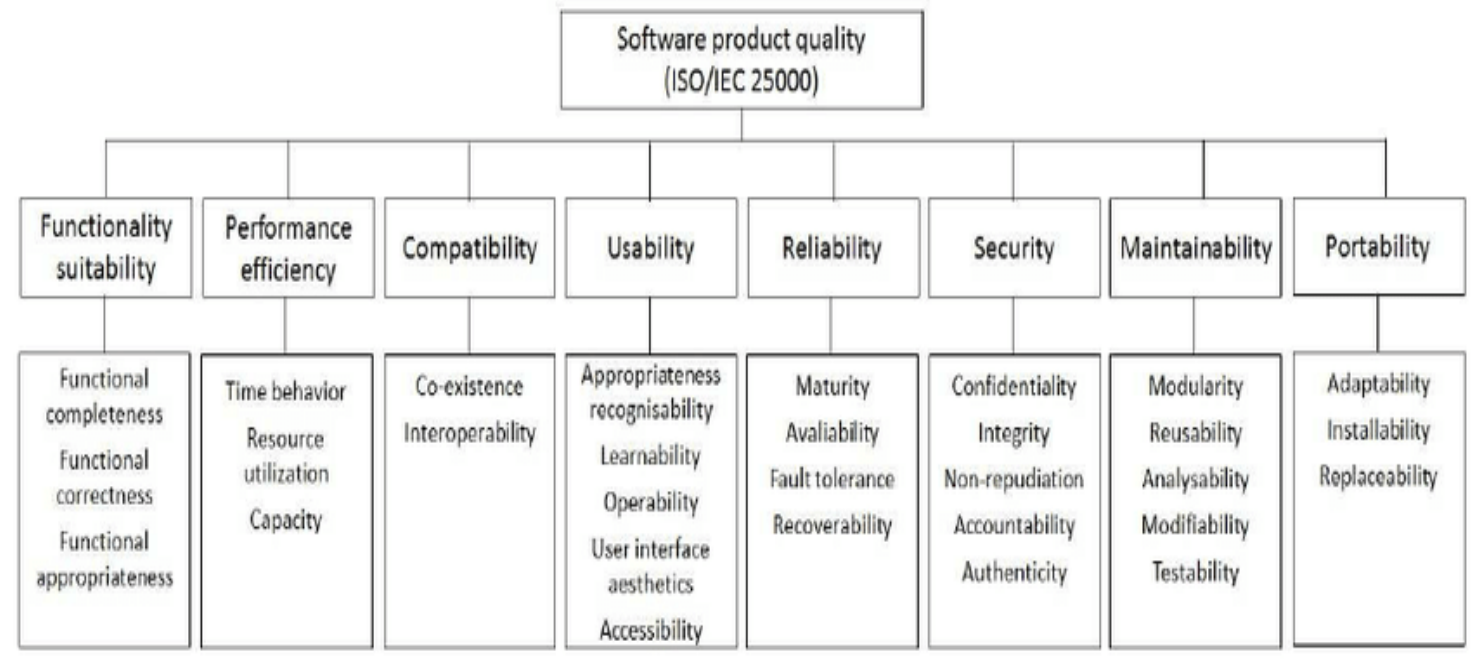

Figure 2. ISO 25101 Model

In the actual testing phase of the smart helmet, both the researchers and participants took all necessary measures in terms of safety precaution specifically while the motorcycle rider is using the smart helmet while riding.

\section{System Design}

The proposed system will help the motorcycle rider in times of critical needs where the emergency response team is needed to locate the said rider. It will also be a tool to locate the motorcycle when the motorcycle is missing or stolen by means of activating its anti-theft feature integrating the GPS location tracker. The integration of cloud infrastructure in which the realtime data are collected by the sensors is stored and analyze. of the proposed hardware and system integration.

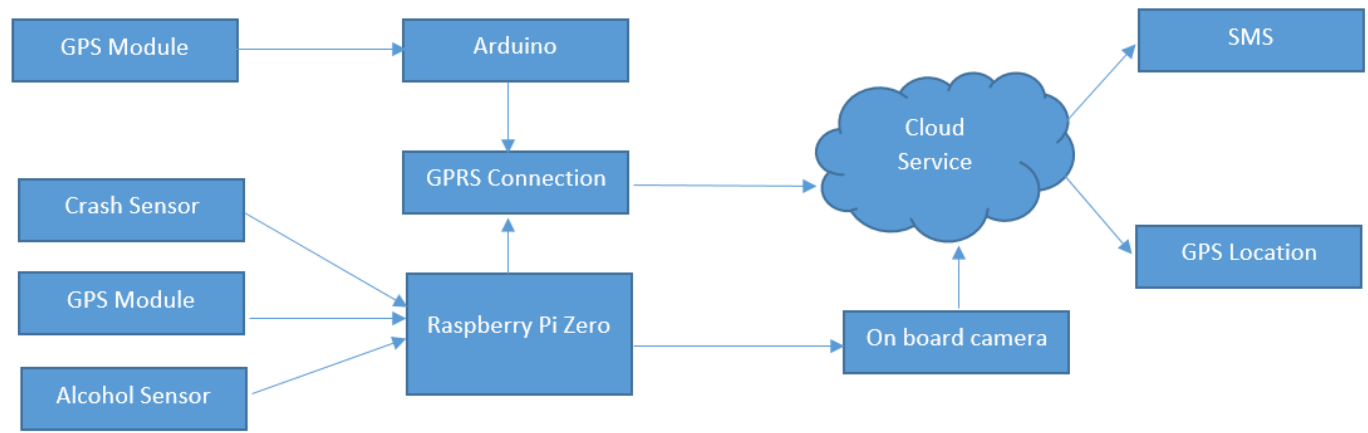

Figure3. Block Diagram of the Smart Motorcycle Helmet System

The main component of the system is the Raspberry Zero-W for the helmet and Arduino Uno for the motorcycle tracking, RPiZero-W is half the size of Raspberry Pi 3 is a single-board PC or system-on-chip running at $1 \mathrm{Ghz}$ processing speed capable handling different type of InputOutput (I/O) either digital or analog sensors thru its 40 pin General Purpose Input Output headers. 
It has a composite RCA video, mini-HDMI 1080p video and audio connection, microSC card slot, built-in wifi, and Bluetooth connection. RPiZero-W will be the controller for the Smart Helmet where the sensor will be connected.

Arduino is the secondary controller installed on the motorcycle itself, its job is to send the GPS location of the motorcycle once it is stolen. The Arduino is independent of the RPiZero-W having its own SMS and GPS module.Data gathered from the sensor which includes GPS, accelerometer, alcohol, and crash sensors are sent to the cloud service portal for real-time analysis.

In the event of an accident specifically a collision or crash will trigger the smart helmet to send a notification to the family or emergency personnel along with the motorcycle rider GPS location using the longitude and latitude coordinates.

\section{Methodology and Procedures}

The researchersused the prototyping methodology in the design and development of Smart Helmet. The methodology consisted of the following phases: determining the objective phase, development phase, refinement phase, testing phase. Under the prototyping method, an iterative process will be implemented, in which trial-and-error between development can be done based on currently known requirements. [17]

\section{Phase I. Determine Objectives}

The researchers collected all required information to meet the objective of the study in Phase I. Primary and secondary sources were used to obtain the necessary data. Based on the interview with motorcycle riders, the need for the quick response coming from the first responder in case of an accident and informing the family is important. Having a device that can do those things can help motorcycle riders.

\section{Phase II. Development Phase}

Phase II is the development phase which is divided into two stages. Stage 1 is the prototyping of the device circuitry on the breadboard. Connecting all sensors and testing sensor data. The sensor includes GPS data - longitude and latitude, sending of SMS, alcohol sensor accuracy. The researchers used open-source software such as Python for creating the scripts in Raspberry Pi Zero, Sketch programming language for the Arduino module. As for the cloud infrastructure the researchers used an EC2 free-tier virtual machine wherein MySQL server is setup. This was where data from the accident is sent (i.e. GPS longitude and latitude, time of the accident, information about the motorcycle rider).

Calibrating the alcohol sensor is one of the difficult parts of the testing. The MQ-135 alcohol sensor is made up of tin dioxide and a layer on aluminum oxide. So any ethyl alcohol present in a breath is oxidized can be detected. The MQ135 alcohol sensor once connected to the Raspberry Pi Zero-W general process input-output (GPIO) terminal generates an analog value number that can be used to calibrate it (Fig.4). For the testing part, thru trial and error, a value higher than 400 can be considered of high alcohol concentration on the motorcycle rider breath. 
Detecting the occurrences of an accident was another problem encountered, using an ADXL345 Accelerometer to measure acceleration, the researchers determined the intensity of vibration the accelerometer generates when impact occurs.

\section{Phase III. Refinement Phase}

Phase III involves re-testing all hardware, sensors connection, and output. Any malfunctioning parts are replaced. The incorrect output from the sensors is recalibrated. Testing of the codes done in python was checked and integration of the Arduino as a separate module for the anti-theft is tested. The researchers removes all malfunctioning components, debug the software for errors. Hence, testing of the prototype happened in this phase.

\section{Phase IV. Demonstration and Testing phase}

Phase IV, after setting up all the components, loading up the SIM card with data, connecting the 12 volts' power bank, the researchers proceeded on demonstrating the device, the researchers showed the smart helmet to 10 motorcycle riders, testing the functionality of the smart helmet how it would work at same time getting their inputs. A few problems arose from the testing phase: sometimes when the GPS signal is weak, an incorrect latitude and longitude value registered. Upon proper inspection of the hardware and software, a mistake was found on the Python code that is used to both the latitude and longitude GPS signal. To test for the crash, the researchers along with participants drop the helmet from five feet to simulate impact of the smart helmet on the ground. With accelerometer registering the impact force triggered the notification module.

\section{RESUlts AND Discussions}

\section{Data Analysis}

The researchers used a quantitative method to analyze the data, using a statistical treatment such as frequency and weighted mean. After finishing the hardware and software development phase of the prototype, the hardware and software underwent alpha and beta testing to assess the functionality of the proposed IoT device using the researchers-made instruments. Alpha and beta testing of the hardware and software play an important role in the software development life cycle. With its usage, the developer should produce a system with no discrepancy. Based on the survey, error or bugs in software cost the US economy $0.6 \%$ on its gross domestic product, $80 \%$ of software company cost is in finding and fixing errors.[18]

Data collected were analyzed using statistical treatment on the following features of the tested device: (a) Accuracy, (b) Efficiency and (c) Functionality.

\section{Rated Functionality of the System}

\begin{tabular}{|ll|c|c|}
\hline \multicolumn{2}{|c|}{ Descriptive Rating } & Weighted Mean & Rating Scale \\
\hline Exceedingly Functional & $(\mathrm{EF})$ & $4.21-5.00$ & 5 \\
\hline Very Functional & $(\mathrm{VF})$ & $3.41-4.20$ & 4 \\
\hline Functional & $(\mathrm{F})$ & $2.61-3.40$ & 3 \\
\hline Somewhat Functional & $(\mathrm{SF})$ & $1.81-2.60$ & 2 \\
\hline Not Functional & $(\mathrm{NF})$ & $1-1.80$ & 1 \\
\hline
\end{tabular}


Rated Accessibility of the System

\begin{tabular}{|ll|c|c|}
\hline \multicolumn{2}{|c|}{ Descriptive Rating } & Weighted Mean & Rating Scale \\
\hline Exceedingly Accessible & (EA) & $4.21-5.00$ & 5 \\
\hline Very Accessible & (VA) & $3.41-4.20$ & 4 \\
\hline Accessible & (A) & $2.61-3.40$ & 3 \\
\hline Somewhat Accessible & (SA) & $1.81-2.60$ & 2 \\
\hline Not Accessible & (NA) & $1-1.80$ & 1 \\
\hline
\end{tabular}

\section{Rated Effectiveness of the System}

\begin{tabular}{|lc|c|l|}
\hline \multicolumn{2}{|c|}{ Descriptive Rating } & Weighted Mean & Rating Scale \\
\hline Exceedingly Effective & $(\mathrm{EE})$ & $4.21-5.00$ & 5 \\
\hline Very Effective & $(\mathrm{VE})$ & $3.41-4.20$ & 4 \\
\hline Effective & $(\mathrm{E})$ & $2.61-3.40$ & 3 \\
\hline Somewhat Effective & $(\mathrm{SE})$ & $1.81-2.60$ & 2 \\
\hline Not Effective & $1 \mathrm{NE})$ & $1-1.80$ & 1 \\
\hline
\end{tabular}

The purpose of this study was to develop a workable prototype that can help motorcycle riders in times of emergency such as when an accident occurs. Using pre-survey questionnaires inputs from participants selected pre-determined functions that would be needed for the proposed smart helmet / IoT device. As shown in Table 2, participants selected four core functions they want to see when the smart helmet is developed, these functions includes GPS tracking, crash detection, SMS notification / alert to the first responders and to the families of the motorcycle rider, and alcohol level detection for alerting the motorcycle rider of the alcohol content detected.

Taking into account the need to test the software and hardware itself, the smart helmet went through the process of alpha and beta testing. Alpha testing involves testing the different functions of the sensors. Within this phase, the researchers encountered issues on the tracking module for the stolen motorcycle. The original plan is to use a single Arduino board, but with the integration of different sensor and a separate module for alert notification when the motorcycle is stolen, the researchers decided to use a Raspberry Pi Zero-W for connecting the sensors (i.e. accelerometer, alcohol sensor) on the helmet and Arduino for the tracking module on the motorcycle itself.

Table 2.Functionality selected by motorcycle riders needed most in an accident

\begin{tabular}{|c|c|}
\hline IoT Device & Functionality \\
\hline & GPS Tracking \\
Crash Detection \\
SMART MOTORCYCLE HELMET & SMS Notification / Alert to first \\
& responders and to the family \\
& Alcohol Level Detection and Alert \\
\hline
\end{tabular}


Assessment of the effectiveness of the working prototype was done on the beta testing phase with ten (10) participants who volunteered to test the smart helmet. The smart helmet was tested on three main items; Accuracy, Efficiency, and Functionality.

Table 3 shows the results on the functionality side of the smart helmet. GPS location of a stolen motorcycle garnering the highest mean of 4.70 an effectiveness of exceedingly functional. This is an indication of the functionality being sought by motorcycle riders how to track down their stolen motorcycle. Checking of alcohol level for motorcycle rider got 4.50. SMS notification garnered 4.40 while 24/7 access to GPS location got 4.10 which the lowest, looking on the description side 4.10 is still considered very functional. All in all, the functionality of the smart helmet based on the general mean is 4.43 which is Exceeding Functional.

Table3.Assessment of the Functionality of Smart Helmet

\begin{tabular}{llcl}
\hline \multicolumn{1}{c}{ Indicators } & Weighted Mean & Description \\
\hline 1. & $\begin{array}{l}\text { The device checks the alcohol level of the } \\
\text { motorcycle rider using the alcohol sensor }\end{array}$ & 4.50 & $\begin{array}{l}\text { Exceedingly } \\
\text { Functional } \\
\text { Exceedingly }\end{array}$ \\
2. & $\begin{array}{l}\text { Real-time GPS location of the motorcycle } \\
\text { when the motorcycle is stolen }\end{array}$ & 4.70 & $\begin{array}{l}\text { Functional } \\
\text { Exceedingly }\end{array}$ \\
3. SMS notification alert is triggered when a & 4.40 & $\begin{array}{l}\text { Functional } \\
\text { Very } \\
\text { Follision or crash is detected }\end{array}$ \\
4. $\begin{array}{l}\text { The motorcycle rider has 24/7 access in the } \\
\text { GPS location in case the motorcycle was } \\
\text { stolen }\end{array}$ & 4.10 & \\
\hline General Mean & $\mathbf{4 . 4 3}$ & $\begin{array}{l}\text { Exceedingly } \\
\text { Functional }\end{array}$ \\
\hline
\end{tabular}

Table 4 illustrates the effectiveness of the smart helmet as tested by the volunteer motorcycle rider participants. The sending of SMS notification in with no signal interruptions or delayed SMS got the highest point of 4.70. The option of editing and updating the motorcycle rider's information using a smart phone connected to the internet got 4.50. While sending and receiving updated GPS coordinates in real-time garnered 4.40. Assessment of the effectiveness of the smart helmet was rated exceedingly accessible with a general mean of 4.53 .

Table 4.Assessment of the Effectiveness of Smart Helmet

\begin{tabular}{llcl}
\hline \multicolumn{1}{c}{ Indicators } & Weighted Mean & Description \\
\hline 1. $\begin{array}{l}\text { Editing of Rider's contact details for } \\
\text { updating is possible or doable }\end{array}$ & 4.50 & $\begin{array}{l}\text { Exceedingly } \\
\text { Effective } \\
\text { Exceedingly } \\
\text { Effective }\end{array}$ \\
2. $\begin{array}{l}\text { No interruption in sending SMS notification } \\
\text { alert to the first responders (emergency } \\
\text { personnel) and family }\end{array}$ & 4.70 & 4.40 & $\begin{array}{l}\text { Exceedingly } \\
\text { Effective }\end{array}$ \\
3. $\begin{array}{l}\text { The device sends the correct and updated } \\
\text { route of the rider in real time manner }\end{array}$ & $\mathbf{4 . 5 3}$ & $\begin{array}{l}\text { Exceedingly } \\
\text { Effective }\end{array}$ \\
\hline
\end{tabular}


As presented in Table 5, the point of 4.80 weighted means indicates that the motorcycle rider can access their personal information. With the ability to access their personal information, the motorcycle rider can edit their information such as person to contact in case of emergency.

Indicators on GPS location notification to families came next with a 4.00 point. This allows the next of kin to be notified of the accident and view where the accident happened by means of the GPS longitude and latitude.

Table 5.Assessment on the Accessibility Utility of Smart Helmet

\begin{tabular}{llll}
\hline \multicolumn{1}{c}{ Indicators } & Weighted Mean & Description \\
\hline 1. & $\begin{array}{l}\text { The rider has 24/7 access regarding his } \\
\text { personal information }\end{array}$ & 4.80 & $\begin{array}{l}\text { Exceedingly } \\
\text { Accessible }\end{array}$ \\
2. $\begin{array}{l}\text { The family of the motorcycle rider can } \\
\text { view the GPS location of the rider in times } \\
\text { of collision or crash as soon as possible } \\
\text { when triggered }\end{array}$ & 4.00 & $\begin{array}{l}\text { Very } \\
\text { Accessible }\end{array}$ \\
\hline General Mean & $\mathbf{4 . 4 0}$ & $\begin{array}{l}\text { Exceedingly } \\
\text { Accessible }\end{array}$ \\
\hline
\end{tabular}

By using a quantitative study, the researchers sought to determine the need to develop a smart helmet capable of being a tool to save the motorcycle rider in times of an emergency such as an accident or collision. By gathering relevant data from the motorcycle riders themselves, the researchers focus on four key features needed by them. These features are GPS location, SMS alert, and notification, crash or impact detection and GPS tracking when the motorcycle is stolen. Looking for the right technology in terms of portability and compactness the researchers proceeded to look into the Internet of Things (IoT) devices and cloud infrastructure specifically Infrastructure As A Service (IsaaS).

Integrating different sensors on one Arduino board proved to be problematical. In the end, the researchers decided to used Raspberry Pi Zero-W as the main controller for the smart helmet were all the sensors are connected and using the Arduino board as the hardware module for the anti-theft notification. With all the sensor integration, the researchers proceeded with the alpha and beta testing. From which a positive feedback results came from the ten (10) volunteer that tested the smart helmet.

\section{CONCLusions And RECommendations}

Based on the gathered results and information from the related literature and studies, the researchers formed the following conclusion. The Smart Motorcycle Helmet is a viable tool or device that can be used to help motorcycle riders in times of emergency. Taking into account that this is just a prototype there are still bugs and errors being encountered but with enough time to do more testing, those can be iron out.

The helmet is intended to be used by motorcycle riders. Part of the integration of the anti-theft module is the implementation of GPS location tracking module. As part of the enhancement that can be added as future features these are as follows: 
International Journal of Computer Science \& Information Technology (IJCSIT) Vol 11, No 3, June 2019

- Integrations of a kill-switch that will turn off the engine of the motorcycle when the motorcycle is stolen.

- Automated kill-switch for the motorcycle engine when the motorcycle rider is above the safety level of alcohol content detected by the alcohol sensor.

\section{REFERENCES}

[1] Mascarinas, E. M. (2016). Study in better safety measures for motorcycles urged - SUNSTAR. Retrieved December 11, 2018, from https://www.sunstar.com.ph/article/111646

[2] L. Ramos. (2018). Road Accidents In The Philippines: Key Figures - eCompareMo eCompareMo.Retrieved December 11, 2018, from https://www.ecomparemo.com/info/roadaccidents-in-the-philippines-key-figures/

[3] Nandu, R., \& Singh, K. (2014). Smart Helmet for Two-Wheelers. Advances in Automobile Engineering, 03(01), 1-2. https://doi.org/10.4172/2167-7670.1000110

[4] Sung, K.-M., Noble, J., Kim, S.-C., Jeon, H.-J., Kim, J.-Y., Do, H.-H., ... Baek, K.-J. (2016). The Preventive Effect of Head Injury by Helmet Type in Motorcycle Crashes: A Rural Korean SingleCenter Observational Study. BioMed Research International, 2016, 1-7. https://doi.org/10.1155/2016/1849134

[5] J. Dodson. (n.d.). Motorcycle Crashes and Brain Injuries | Jim Dodson Law. Retrieved December 11, 2018, from https://www.jimdodsonlaw.com/library/motorcycle-crashes-and-brain-injuries.cfm

[6] W. Tan. (2018). WHO PH: Over 90\% of Motorcycle Deaths Didn't Wear Helmets - Carmudi Philippines. Retrieved December 18, 2018, from https://www.carmudi.com.ph/journal/philippines90-motorcycle-deaths-didnt-wear-helmets/

[7] Lahausse, J. A., Fildes, B. N., Page, Y., \& Fitzharris, M. P. (2008). The potential for automatic crash notification systems to reduce road fatalities. Annals of Advances in Automotive Medicine. Association for the Advancement of Automotive Medicine. Annual Scientific Conference, 52, 85-92. Retrieved from http://www.ncbi.nlm.nih.gov/pubmed/19026225

[8] M. Glasscoe. (n.d.). What is GPS? Retrieved December 11, 2018, from http://scecinfo.usc.edu/education/k12/learn/gps1.htm

[9] Brodsky, H. (n.d.). Emergency Medical Service Rescue Time in Fatal Road Accidents. Retrieved from http://onlinepubs.trb.org/Onlinepubs/trr/1990/1270/1270-011.pdf

[10] J. Porter. (2018). The History of IoT (Internet of Things) and How It's Changed Today. Retrieved December 18, 2018, from https://www.techprevue.com/history-iot-changed-today/

[11] Vishal, D., Afaque, H. S., Bhardawaj, H., \& Ramesh, T. K. (2018). IoT-driven road safety system. International Conference on Electrical, Electronics, Communication Computer Technologies and Optimization Techniques, ICEECCOT 2017, 2018-Janua, 862-866. https://doi.org/10.1109/ICEECCOT.2017.8284624

[12] Dickenson. (2016). How IoT and machine learning can make our roads safer | TechCrunch. Retrieved December 18, 2018, from https://techcrunch.com/2016/07/13/how-iot-and-machinelearning-can-make-our-roads-safer/ 
International Journal of Computer Science \& Information Technology (IJCSIT) Vol 11, No 3, June 2019

[13] Faizan Manzoor, S. A. B. (2017). Faaz smart helmet, 6(6), 332-335.

[14] Hobby, K. C., Gowing, B., \& Matt, D. P. (2016). Smart helmet, 5(3), 660-663.

[15] Khaja, M., Aatif, A., \& Manoj, A. (2017). Smart Helmet Based On IoT Technology, 5(Vii), 409413.

[16] Motorcyclist age group and gender data - TAC - Transport Accident Commission. (n.d.). Retrieved April 20, 2019, from http://www.tac.vic.gov.au/road-safety/statistics/summaries/motorcycle-crashdata/motorcyclist-age-group-and-gender-data

[17] Amir, G. (n.d.). Prototyping Model in Software Development and Testing. Retrieved January 22, 2019, from https://www.testingexcellence.com/prototyping-model-software-development/

[18] The Importance of Alpha \&amp; Beta Testing Services | Software Testing Tips and Best Practices. (n.d.). Retrieved April 21, 2019, from https://blog.testmatick.com/2016/04/19/the-importance-ofalpha-beta-testing-services/

\section{AUTHORS}

Dr. Marlon I. Tayag is a full-time Associate Professor at Holy Angel University and teaches Cyber Security subjects on Ethical Hacking and Forensic. He earned the degree of Doctor in Information Technology from St. Linus University in 2015 and is currently taking up Doctor of Philosophy in Computer Science at Technological Institute of the Philippines - Manila. Dr. Tayag is Cisco Certified Network Associate, 210-250 CCNA Understanding Cisco Cybersecurity Fundamentals and Fluke CCTTA - Certified Cabling Test Technician Associate. Microsoft Certified Professional and Microsoft Certified Educator.

Dr. Ma. Emmalyn A. V. Capuno is a currently the Dean of the Faculty of Information Technology of Future University Sudan with the academic rank of Associate Professor; a position she has been holding since 2009. She earned the degree of Doctor of Philosophy in Information Technology Management from Colegio de San Juan Letran - Calamba, Philippines in 2005. Her teaching and research expertise includes Operating Systems, Knowledge Management, Business Intelligence and many more.
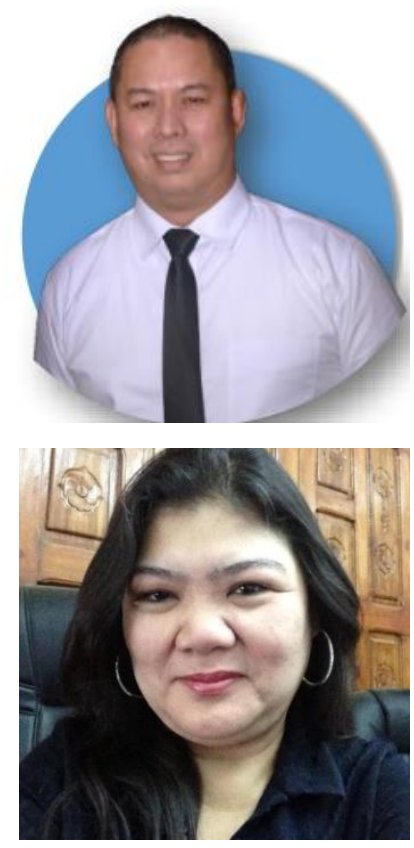